\title{
Relationship of Oxidative Stress, Inflammation, and the Risk of Metabolic Syndrome in Patients with Oral Cancer
}

\author{
Bor-Jen Lee $\mathbb{D}^{1,2}$ Man-Yee Chan, ${ }^{3,4}$ Han-Yu Hsiao, ${ }^{3}$ Chia-Hua Chang, ${ }^{5}$ Li-Ping Hsu, ${ }^{5}$ \\ and Ping-Ting Lin ${ }^{5,6}$ \\ ${ }^{1}$ Department of Critical Care Medicine, Taichung Veterans General Hospital, Taichung 40705, Taiwan \\ ${ }^{2}$ School of Medicine, Chung Shan Medical University, Taichung 40201, Taiwan \\ ${ }^{3}$ Division of Oral and Maxillofacial Surgery, Department of Dentistry, Taichung Veterans General Hospital, Taichung 40705, Taiwan \\ ${ }^{4}$ School of Dentistry, College of Oral Medicine, Chung Shan Medical University, Taichung 40201, Taiwan \\ ${ }^{5}$ Department of Nutrition, Chung Shan Medical University, Taichung 40201, Taiwan \\ ${ }^{6}$ Department of Nutrition, Chung Shan Medical University Hospital, Taichung 40201, Taiwan
}

Correspondence should be addressed to Ping-Ting Lin; apt810@csmu.edu.tw

Received 13 February 2018; Revised 17 April 2018; Accepted 18 April 2018; Published 21 May 2018

Academic Editor: Giuseppe Cirillo

Copyright (c) 2018 Bor-Jen Lee et al. This is an open access article distributed under the Creative Commons Attribution License, which permits unrestricted use, distribution, and reproduction in any medium, provided the original work is properly cited.

Oral cancer is the fifth leading cause of cancer death in Taiwan, and the prevalence of metabolic syndrome (MS) has also increased globally. The purpose of this study was to investigate the correlations between the components of MS and oxidative stress and inflammation in patients with oral cancer based on their areca-nut-chewing habits. Two hundred patients diagnosed with oral cancer were recruited, and metabolic parameters, oxidative stress, antioxidant enzyme activities, and inflammatory markers were measured. $63 \%$ of the subjects have concomitant MS. Subjects who had an areca-nut-chewing habit had significantly higher levels of fasting glucose $(p=0.04)$, oxidative stress $(p=0.02)$, and inflammatory markers $(p=0.02)$ than those who never chewed. High-density lipoprotein-cholesterol level $(p=0.03)$ and superoxidase dismutase activity $(p=0.02)$ were significantly lower in individuals who had chewed or were currently chewers. Areca-nut-chewing habit was associated with the increased risks for MS and hypertriglyceridemia; the components of MS were positively correlated with oxidative stress and inflammation. In conclusion, patients with oral cancer who had an areca-nut-chewing habit exhibited higher levels of oxidative stress and inflammation, which might be related to an increased risk of MS.

\section{Introduction}

According to the latest cancer statistics from the American Cancer Society, Americans accounted for the estimated $30 \%$ of the new cases of oral cancer and $2 \%$ of the oralcancer-related deaths that occurred in the US in 2017 [1]. By contrast, almost $60 \%$ of all new cases of oral cancer occurred in Asia, and 68\% of oral-cancer-related deaths occurred in the Asian population [2]. In Taiwan, oral cancer is the fifth leading cause of cancer deaths in both sexes and is the fourth leading cause of cancer deaths in men [3]. The areca-nut-chewing habit is an independent risk factor for oral cancer [4] as the constituents of areca nut ingredients, such as areca alkaloids, have been shown to be carcinogenic to humans; furthermore, areca-nut-specific nitrosamines are genotoxic and induce tumor progression [5]. In addition to the carcinogenic effects of areca nut chewing, harmful relationships between this habit and metabolic syndrome (MS) [6-9], type 2 diabetes $[9,10]$, and cardiovascular disease $[9,11,12]$ have also been observed. In clinical practice, we usually recommend that patients with oral cancer should abstain from areca nut chewing. However, no research has followed the status of metabolic parameters of oral cancer patients after quitting areca nut chewing.

It is well known that tumor promotion is associated with prooxidant status [13], as reactive oxygen species (ROS) participate in the progression of carcinogenesis [13, 14]. During areca nut chewing, ROS are produced, which attack salivary 
proteins, change the structure of oral mucosa, and activate the inflammatory responses [15]. There is limited clinical research assessing the status of oxidative stress and inflammatory and metabolic parameters in individuals with oral cancer even if they quit areca nut chewing. Therefore, the aim of the present clinical study was to investigate the relationship between the areca-nut-chewing habit and oxidative stress, inflammation, and the risk of MS in the patients with oral cancer based on their areca-nut-chewing habits.

\section{Materials and Methods}

2.1. Participants. This was an observational study. Patients diagnosed with oral cancer and who underwent tumor resection were recruited from the Department of Dentistry at Taichung Veterans General Hospital. We excluded patients younger than 20 years of age or older than 80 years of age, as well as those with a history or current diagnosis of liver or renal disease and those taking antioxidant vitamins. Informed consent was obtained from each subject. This study was approved by the Institutional Review Board of Taichung Veterans General Hospital, Taiwan. The following data were recorded from the medical questionnaire administered to all subjects: age, blood pressure, areca-nut-chewing habits (including current users, those with a history of areca nut chewing (defined as quitting areca nut chewing $\geq 6$ months prior), and nonusers), smoking and drinking habits, and exercise frequency. Body weight, height, and waist and hip circumferences were measured; the body mass index (BMI) and the ratio of waist to hip were calculated. The diagnostic criteria for MS in Taiwan are based on the guidelines of the Administration of Health Promotion, Ministry of Health and Welfare, Taiwan (2007). Subjects were considered to have MS if they had three of the following five characteristics: (1) abdominal obesity (waist circumference $\geq 90 \mathrm{~cm}$ in males and $\geq 80 \mathrm{~cm}$ in females), (2) impaired fasting glucose (fasting glucose $(\mathrm{FG}) \geq 5.6 \mathrm{mM}$ ), (3) hypertriglyceridemia (triglyceride $(\mathrm{TG}) \geq 1.7 \mathrm{mM}$ ), (4) low levels of high-density lipoprotein-cholesterol (HDL-C) $<1.0 \mathrm{mM}$ in males and $<1.3 \mathrm{mM}$ in females, and (5) increased blood pressure (systolic blood pressure $(\mathrm{SBP}) \geq 130 \mathrm{mmHg}$ and diastolic blood pressure (DBP) $\geq 85 \mathrm{mmHg}$ ). Subjects taking antidiabetic, antihypertensive, and lipid-lowering medications were considered to have elevated FG, elevated blood pressure, and dyslipidemia, respectively.

2.2. Blood Collection and Biochemical Measurement. Fasting venous blood samples $(15 \mathrm{~mL})$ were collected in vacutainer tubes (Becton Dickinson, Rutherford, NJ, USA) with and without anticoagulant as required. Plasma and serum samples were prepared after centrifugation $\left(3000 \mathrm{rpm}, 4^{\circ} \mathrm{C}\right.$, and 15 minutes). Hematological parameters, such as FG and lipid profiles, were measured using an automated biochemical analyzer (Hitachi, Tokyo, Japan). Plasma MDA (malondialdehyde) was determined using the thiobarbituric acid reactive substance method [16]. The methods for measuring CAT, SOD, and GPx in red blood cells have been previously described [17-19]. First, red blood cells (RBC) were diluted with $25 \mathrm{x}$ sodium phosphate buffer for superoxide dismutase
(SOD) and glutathione peroxidase (GPx) measurement and 250x sodium phosphate buffer for catalase (CAT) measurement. SOD activity was measured by the decreasing rate of pyrogallol autoxidation under alkali conditions ( $\mathrm{pH} 8.2$ ) and then analyzed spectrophotometrically at $325 \mathrm{~nm} \mathrm{[18].}$ CAT activity was measured spectrophotometrically at $240 \mathrm{~nm}$ with hydrogen peroxide as substrate [19]. GPx activity was measured with cumene hydroperoxide as substrate coupled with glutathione reductase and then analyzed spectrophotometrically at $340 \mathrm{~nm}$ [17]. Protein contents of RBC were determined based on the biuret reaction of the BCA Protein Assay Reagent Kit (Thermo Scientific, Rockford, IL, USA), and the antioxidant enzyme activities were expressed as the units/mg of protein. Serum level of high-sensitivity C-reactive protein (hs-CRP) was quantified by particleenhanced immunonephelometry with an image analyzer (Dade Behring, Deerfield, IL, USA).

2.3. Statistical Analysis. Data were analyzed using SigmaPlot software (version 12.0, Systat Software, Inc., San Jose, CA, USA). The normality of the distribution of the variables was evaluated using the Shapiro-Wilk test. For categorical response variables, the differences between the two groups were assessed using the Chi-square test or Fisher's exact test. One-way ANOVA analyses were performed to examine the differences in the patients who currently, formerly, and never chewed areca nut, and post hoc tests were further used to compare the differences among the three groups. To examine the correlations between the components of MS and oxidative stress and inflammation, Spearman rank order correlation was used. Logistical regression analyses were further used to examine the correlation between the areca-nutchewing habit and the components of MS after adjusting for age and gender. The results were considered statistically significant at $p<0.05$. The values are presented in the text as the means \pm standard deviation (medians).

\section{Results}

3.1. Demographic Characteristcs of the Subjects. Two hundred patients with oral cancer were included and were made to complete the data analyses in the present study. A total of $95 \%$ of the oral cancer patients were male with a mean age of 54 years old. A total of $63 \%$ of the subjects suffered from MS, 58\% suffered from abdominal obesity, $76 \%$ suffered from borderline hypertension, $66 \%$ suffered from borderline hyperglycemia, $49 \%$ suffered from borderline hypertriglyceridemia, and $47 \%$ suffer from low levels of HDL-C. With regard to areca nut habits, $19 \%$ of the subjects were current users, $71 \%$ of the subjects were former users, and $11 \%$ of the subjects had never chewed areca nut. In Table 1, the demographic characteristics of subjects are stratified by their areca-nut-chewing habits. Subjects who had a current arecanut-chewing habit had a significantly lower mean age and higher frequency of smoking and alcohol use. A higher incidence of abdominal obesity, elevated blood pressure, and increased recurrence rate for oral cancer and incidence of hypertensive disease history were observed in former areca nut chewers. 
TABLE 1: Demographic characteristics of the subjects according to areca nut use.

\begin{tabular}{|c|c|c|c|c|}
\hline & $\begin{array}{c}\text { Current chewers } \\
(n=38)\end{array}$ & $\begin{array}{l}\text { Former chewers } \\
\quad(n=141)\end{array}$ & $\begin{array}{l}\text { Never chewers } \\
\quad(n=21)\end{array}$ & $p$ values \\
\hline Males $(n, \%)$ & $37(97 \%)$ & $137(97 \%)$ & $15(71 \%)$ & $<0.01$ \\
\hline Age (y) & $50 \pm 9(51.0)^{1, \mathrm{a}}$ & $55 \pm 10(56.0)^{\mathrm{b}}$ & $54 \pm 12(55.0)^{\mathrm{a}, \mathrm{b}}$ & 0.03 \\
\hline SBP (mmHg) & $132 \pm 16(132.0)$ & $137 \pm 20(135.0)$ & $131 \pm 16(127.0)$ & 0.24 \\
\hline $\mathrm{DBP}(\mathrm{mmHg})$ & $85 \pm 12(83.5)$ & $88 \pm 15(86.0)$ & $85 \pm 9(84.0)$ & 0.55 \\
\hline Waist $(\mathrm{cm})$ & $91 \pm 10(89.0)$ & $92 \pm 11(93.0)$ & $96 \pm 10(96.0)$ & 0.13 \\
\hline BMI $\left(\mathrm{kg} / \mathrm{m}^{2}\right)$ & $25 \pm 4(24.4)$ & $26 \pm 7(25.8)$ & $25 \pm 5(24.3)$ & 0.75 \\
\hline $\operatorname{MS}(n, \%)$ & $24(63 \%)$ & $90(64 \%)$ & $11(52 \%)$ & 0.60 \\
\hline Abdominal obesity ${ }^{2}(n, \%)$ & $17(45 \%)$ & $86(61 \%)$ & $12(57 \%)$ & 0.08 \\
\hline High blood pressure ${ }^{3}(n, \%)$ & $25(66 \%)$ & $113(80 \%)$ & $14(67 \%)$ & 0.04 \\
\hline Hyperglycemia $^{4}(n, \%)$ & $27(71 \%)$ & $96(68 \%)$ & $9(43 \%)$ & 0.26 \\
\hline Hypertriglyceridemia $^{5}(n, \%)$ & $18(47 \%)$ & $69(49 \%)$ & $11(52 \%)$ & 0.83 \\
\hline Low HDL-C ${ }^{6}(n, \%)$ & $21(55 \%)$ & $62(44 \%)$ & $11(52 \%)$ & 0.22 \\
\hline Smoker ${ }^{7}$ & & & & $<0.01$ \\
\hline Current $(n, \%)$ & $25(66 \%)$ & $56(40 \%)$ & $7(33 \%)$ & \\
\hline Ever $(n, \%)$ & $11(29 \%)$ & $66(47 \%)$ & $6(29 \%)$ & \\
\hline Never $(n, \%)$ & $2(5 \%)$ & $19(13 \%)$ & $8(38 \%)$ & \\
\hline Alcohol use $e^{8}$ & & & & $<0.01$ \\
\hline Current $(n, \%)$ & $16(42 \%)$ & $55(39 \%)$ & $4(19 \%)$ & \\
\hline $\operatorname{Ever}(n, \%)$ & $12(32 \%)$ & $48(34 \%)$ & $2(10 \%)$ & \\
\hline $\operatorname{Never}(n, \%)$ & $10(26 \%)$ & $38(27 \%)$ & $15(71 \%)$ & \\
\hline $\operatorname{Exercise}^{9}(n, \%)$ & $8(21 \%)$ & $59(42 \%)$ & $8(38 \%)$ & 0.06 \\
\hline Cancer recurrence $(n, \%)$ & $1(3 \%)$ & $57(40 \%)$ & $2(10 \%)$ & $<0.01$ \\
\hline TNM stages $^{10}(n, \%)$ & & & & 0.90 \\
\hline Stage 0 & 0 & $2(1.4 \%)$ & 0 & \\
\hline Stage I & $8(21.1 \%)$ & $29(20.6 \%)$ & $6(28.6 \%)$ & \\
\hline Stage II & $10(26.3 \%)$ & $48(34.0 \%)$ & $4(19.0 \%)$ & \\
\hline Stage III & $7(18.4 \%)$ & $18(12.8 \%)$ & $5(23.8 \%)$ & \\
\hline Stage IVA & $12(31.6 \%)$ & $34(24.1 \%)$ & $6(28.6 \%)$ & \\
\hline Stage IVB & $1(2.6 \%)$ & $3(2.1 \%)$ & 0 & \\
\hline Stage IVC & 0 & $1(0.7 \%)$ & 0 & \\
\hline \multicolumn{5}{|l|}{ Disease history } \\
\hline Hypertension $(n, \%)$ & $5(13 \%)$ & $38(27 \%)$ & $2(10 \%)$ & 0.06 \\
\hline Diabetes $(n, \%)$ & $5(13 \%)$ & $25(18 \%)$ & $2(10 \%)$ & 0.55 \\
\hline \multicolumn{5}{|l|}{ Family history } \\
\hline Oral cancer $(n, \%)$ & $1(3 \%)$ & $5(4 \%)$ & 0 & 0.67 \\
\hline Hypertension $(n, \%)$ & $9(24 \%)$ & $39(28 \%)$ & $8(38 \%)$ & 0.49 \\
\hline Diabetes $(n, \%)$ & $4(11 \%)$ & $28(20 \%)$ & $3(14 \%)$ & 0.37 \\
\hline
\end{tabular}

${ }^{1}$ Mean \pm SD (median). ${ }^{2}$ Waist circumferences: $\geq 90 \mathrm{~cm}$ (males) and $\geq 80 \mathrm{~cm}$ (females). ${ }^{3} \mathrm{SBP} \geq 130 \mathrm{mmHg}$ or DBP $\geq 85 \mathrm{mmHg}$, or taking antihypertensive drugs. ${ }^{4}$ Fasting glucose $\geq 5.6 \mathrm{mM}$ or taking hypoglycemic drugs. ${ }^{5} \mathrm{TG} \geq 1.7 \mathrm{mM}$ or taking antihyperlipidemia drugs. ${ }^{6} \mathrm{HDL}-\mathrm{C}:<1.0 \mathrm{mM}$ (males) and $<1.3 \mathrm{mM}$ (females). ${ }^{7}$ Smoker: individuals regularly smoking one or 1 more cigarette per day. ${ }^{8}$ Alcohol use: individuals regularly consuming one or 1 more drink per day. ${ }^{9}$ Exercise: individuals exercise regularly at least 3 times per week. ${ }^{10}$ Six subjects who had formerly chewed areca nut had no TNM data. BMI, body mass index; DBP, diastolic blood pressure; SBP, systolic blood pressure; TNM, tumor-node-metastasis. ${ }^{\mathrm{a}, \mathrm{b}}$ Values with different superscripts were significantly different among the three groups.

3.2. Levels of Metabolic Parameters. The levels of glucose and lipid profiles of the subjects as stratified by their areca-nutchewing status are shown in Table 2. Subjects who were currently chewing or had formerly chewed areca nut had a significantly higher FG level than those who never chewed $(p=0.04)$. The level of HDL-C was significantly lower in subjects who were currently chewing areca nut than in those who had never chewed $(p=0.03)$.

3.3. Levels of Oxidative Stress, Inflammation, and Antioxidant Enzymes. The levels of oxidative stress, inflammatory markers, and antioxidant enzyme activities are shown in 
TABLE 2: Levels of metabolic parameters based on areca nut use.

\begin{tabular}{lcccc}
\hline & $\begin{array}{c}\text { Current chewers } \\
(n=38)\end{array}$ & $\begin{array}{c}\text { Former chewers } \\
(n=141)\end{array}$ & $\begin{array}{c}\text { Never chewers } \\
(n=21)\end{array}$ & $p$ values \\
\hline FG $(\mathrm{mM})$ & $6.6 \pm 1.7(5.9)^{1, \mathrm{a}}$ & $7.3 \pm 3.6(6.0)^{\mathrm{a}}$ & $5.6 \pm 0.9(5.4)^{\mathrm{b}}$ & 0.04 \\
TC $(\mathrm{mM})$ & $4.8 \pm 0.9(4.6)$ & $4.7 \pm 1.0(4.7)$ & $4.7 \pm 0.9(4.8)$ \\
TG $(\mathrm{mM})$ & $2.2 \pm 1.3(1.9)$ & $2.4 \pm 2.1(1.7)$ & $1.7 \pm 1.0(1.4)$ & 0.89 \\
LDL-C $(\mathrm{mM})$ & $3.0 \pm 0.7(2.8)$ & $1.2 \pm 0.9(2.7)$ & $2.9 \pm 0.9(2.8)$ & 0.37 \\
HDL-C $(\mathrm{mM})$ & $1.0 \pm 0.2(1.0)^{\mathrm{a}}$ & $1.1 \pm 0.3(1.0)^{\mathrm{a}, \mathrm{b}}$ & $1.3 \pm 0.3(1.2)^{\mathrm{b}}$ & 0.51 \\
TC/HDL-C & $5.2 \pm 1.7(5.0)$ & $4.6 \pm 1.5(4.3)$ & $4.3 \pm 1.4(3.9)$ & 0.03 \\
\hline
\end{tabular}

${ }^{1}$ Mean \pm SD (median). FG, fasting glucose; HDL-C, high-density lipoprotein-cholesterol; LDL-C, low-density lipoprotein-cholesterol; TC, total cholesterol; TG, triglyceride. ${ }^{\mathrm{a}, \mathrm{b}}$ Values with different superscripts were significantly different among the three groups.
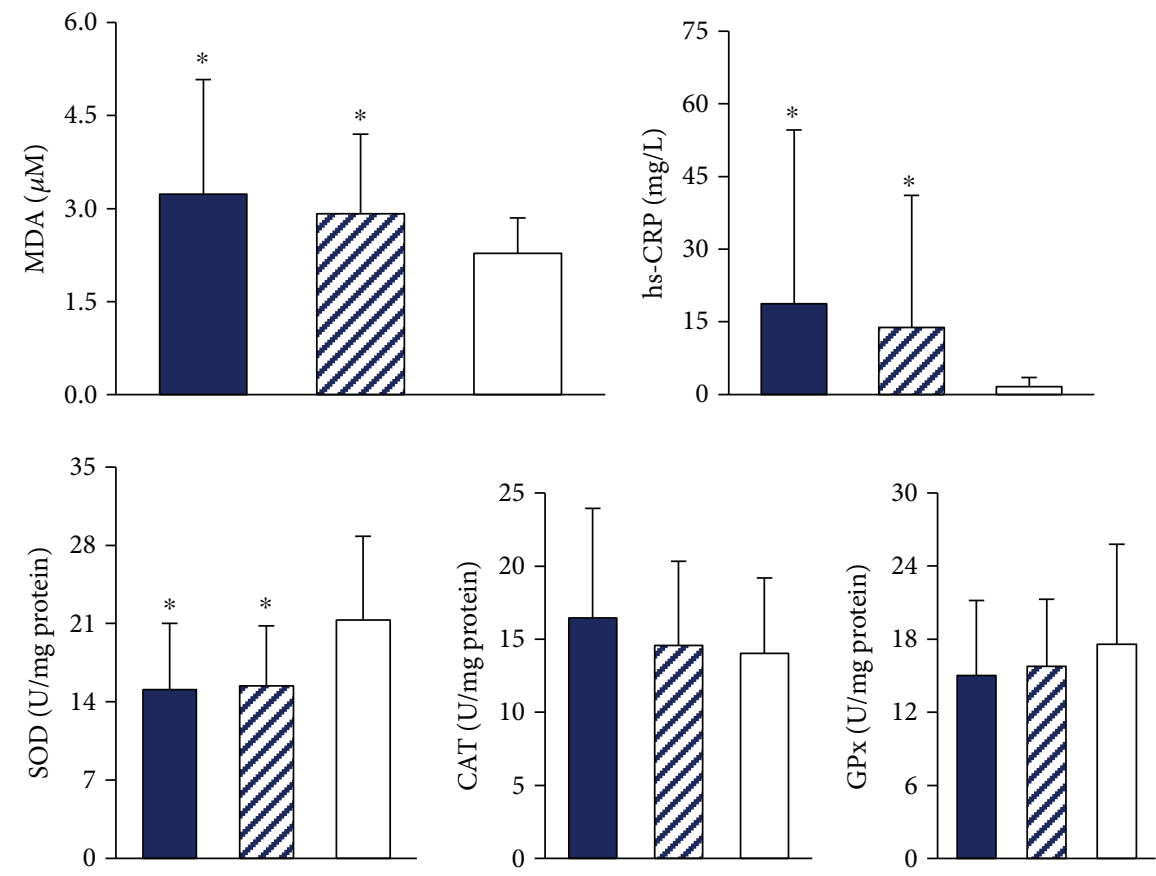

FIGURE 1: Levels for oxidative stress, inflammatory markers, and antioxidant enzyme activities based on areca nut use. CAT, catalase activity; MDA, malondialdehyde; GPx, glutathione peroxidase; hs-CRP, high-sensitivity C-reactive protein; SOD, superoxide dismutase. ${ }^{*}$ Values were significantly different from subjects who never chewed areca nut. (Blue-colored bar) current chewers, (striped bar) former chewers, and (white bar) never chewers.

Figure 1. Subjects who were currently chewing or had formerly chewed areca nut had significantly higher levels of oxidative stress (MDA, $p=0.02$ ) and inflammation (hs-CRP, $p=0.02$ ) than those who had never chewed; meanwhile, a significantly lower level of SOD activity was found in current and former chewers $(p=0.02)$.

3.4. Correlations between Components of Metabolic Syndrome and Oxidative Stress and Inflammation. The correlations between components of MS and both oxidative stress and inflammation are shown in Table 3. MS was significantly positively correlated with oxidative stress $(r=0.14, p=0.01)$ and inflammatory markers $(r=0.17, p=0.02)$. Regarding specific parameters of MS, hyperglycemia $(r=0.13, p=0.01)$ and hypertriglyceridemia $(r=0.14, p=0.01)$ were significantly positively correlated with oxidative stress. Furthermore, abdominal obesity $(r=0.12, p=0.02)$, hyperglycemia $(r=0.24, p<0.01)$, and low HDL-C $(r=0.26, p<0.01)$ were significantly positively correlated with inflammation.

We also examined the correlation between areca nut use and the risk of MS after adjusting for age and gender and the data are shown in Table 4. Subjects with a current areca-nutchewing habit had significantly increased risks of MS (odds ratio $=2.30, p=0.03$ ) and hyperglycemia (odds ratio $=2.71$, $p<0.01)$.

\section{Discussion}

Some community-based health population surveys have reported that oral precancerous lesions were significantly correlated with the components of MS and were related to areca nut chewing [10,20-22]. Areca nut is a major contributor of oral cancer [4], and nearly $90 \%$ of patients with oral cancer in the present study had a history of areca nut 
TABLE 3: Correlations between components of metabolic syndrome and oxidative stress and inflammation.

\begin{tabular}{|c|c|c|c|c|c|c|}
\hline & $\begin{array}{l}\text { Metabolic } \\
\text { syndrome }^{2}\end{array}$ & $\begin{array}{c}\text { Abdominal } \\
\text { obesity }^{3}\end{array}$ & $\begin{array}{l}\text { High blood } \\
\text { pressure }^{4}\end{array}$ & $\begin{array}{c}\text { Hyperglycemia }^{5} \\
r^{1}\end{array}$ & Hypertriglyceridemia $^{6}$ & Low HDL-C $\mathrm{C}^{7}$ \\
\hline \multicolumn{7}{|l|}{ Oxidative stress } \\
\hline $\operatorname{MDA}(\mu \mathrm{M})$ & $0.14^{*}$ & 0.03 & 0.05 & $0.13^{*}$ & $0.14^{*}$ & -0.04 \\
\hline \multicolumn{7}{|l|}{ Antioxidant capacity } \\
\hline $\mathrm{SOD}$ (U/mg protein) & -0.09 & -0.06 & -0.02 & -0.08 & -0.04 & -0.08 \\
\hline CAT (U/mg protein) & -0.03 & -0.07 & -0.03 & -.001 & 0.01 & 0.02 \\
\hline GPx (U/mg protein) & 0.05 & 0.01 & -0.04 & 0.09 & -0.01 & 0.05 \\
\hline \multicolumn{7}{|l|}{ Inflammatory markers } \\
\hline hs-CRP (mg/L) & $0.17^{*}$ & $0.12^{*}$ & -0.03 & $0.24^{* *}$ & -0.00 & $0.26^{* *}$ \\
\hline
\end{tabular}

${ }^{1}$ Correlation coefficient $(r) .{ }^{2}$ Yes $=1$ and no $=0 .{ }^{3}$ Waist circumferences: $\geq 90 \mathrm{~cm}$ (males) and $\geq 80 \mathrm{~cm}$ (females). ${ }^{4} \mathrm{SBP} \geq 130 \mathrm{mmHg}$ or DBP $\geq 85 \mathrm{mmHg}$, or taking antihypertensive drugs. ${ }^{5}$ Fasting glucose $\geq 5.6 \mathrm{mM}$ or taking hypoglycemic drugs. ${ }^{6} \mathrm{TG} \geq 1.7 \mathrm{mM}$ or taking antihyperlipidemia drugs. ${ }^{7} \mathrm{HDL}-\mathrm{C}$ : $<1.0 \mathrm{mM}$ (males) and $<1.3 \mathrm{mM}$ (females). CAT, catalase activity; MDA, malondialdehyde; GPx, glutathione peroxidase; hs-CRP, high-sensitivity C-reactive protein; SOD, superoxide dismutase. ${ }^{*} p<0.05$ and ${ }^{* *} p<0.01$.

TABLE 4: Correlations between areca nut use and the risk of metabolic syndrome after adjusting for age and gender.

\begin{tabular}{|c|c|c|c|c|}
\hline & \multirow{2}{*}{ Never use } & \multicolumn{3}{|c|}{ Areca nut use } \\
\hline & & Odds ratio & $95 \%$ CI & $p$ values \\
\hline Metabolic syndrome & \multirow{6}{*}{1.00} & 2.30 & $0.12-3.27$ & 0.03 \\
\hline Abdominal obesity ${ }^{1}$ & & 1.21 & $0.58-2.54$ & 0.61 \\
\hline High blood pressure ${ }^{2}$ & & 1.66 & $0.76-3.65$ & 0.21 \\
\hline Hyperglycemia $^{3}$ & & 2.71 & $1.29-5.69$ & $<0.01$ \\
\hline Hypertriglyceridemia $^{4}$ & & 0.83 & $0.39-1.78$ & 0.63 \\
\hline Low HDL-C ${ }^{5}$ & & 0.86 & $0.40-1.84$ & 0.70 \\
\hline
\end{tabular}

${ }^{1}$ Waist circumferences: $\geq 90 \mathrm{~cm}$ (males) and $\geq 80 \mathrm{~cm}$ (females). ${ }^{2}$ Systolic blood pressure $\geq 130 \mathrm{mmHg}$ or diastolic blood pressure $\geq 85 \mathrm{mmHg}$, or taking antihypertensive drugs. ${ }^{3}$ Fasting glucose $\geq 5.6 \mathrm{mM}$ or taking hypoglycemic drugs. ${ }^{4}$ Triglyceride $\geq 1.7 \mathrm{mM}$ or taking antihyperlipidemia drugs. ${ }^{5} \mathrm{HDL}-\mathrm{C}$ : $<1.0 \mathrm{mM}$ (males) and $<1.3 \mathrm{mM}$ (females). CI, confidence interval; HDL-C, high-density lipoprotein-cholesterol.

chewing. Interestingly, $70 \%$ of those patients quit areca nut chewing for a median of 6.3 years. However, higher levels of oxidative stress and inflammatory status were still detected in individuals who quit areca nut chewing (Figure 1). Approximately $60 \%$ of the patients in the present study suffer from MS. Among the components of MS, the incidence of high blood pressure (81\%) and abdominal obesity (62\%) was significantly higher in those patients who had ever chewed areca nut, even those who had quit. Additionally, areca nut use was significantly related to an increase in the risk of MS, particularly hyperglycemia (Table 4), and the components of MS, such as abdominal obesity, hyperglycemia, hypertriglyceridemia, or low HDL-C level was significantly positively correlated with oxidative stress and inflammation (Table 3). Thus, we proposed that the patients with oral cancer who have a history of chewing areca nut might present higher levels of oxidative stress and inflammation, further increasing the risk of MS. Some molecular mechanisms have been thoroughly investigated, and studies have shown that areca nut contents of hydroxychavicol and arecoline compounds which may induce ROS production, cause cell cycle aberration and cell irregular cellular differentiation $[23,24]$, induce platelet aggregation [25] and inflammation
$[26,27]$, and are related to the malignant transformation precancerous oral lesions [28].

Among the components of MS, hyperglycemia is the most significant abnormal metabolic condition in patients with oral cancer who have or had an areca-nut-chewing habit. Approximately $62 \%$ of patients with oral cancer who have a current or had a former areca-nut-chewing habit suffered from hyperglycemia (Table 1). Areca nut and the associated nitrosamines might promote glucose intolerance due to central obesity [29-31]. Approximately half of our subjects $(58 \%)$ had abdominal obesity, $76 \%$ of whom had a history of areca nut chewing. The mechanism by which areca nut promotes hyperglycemia might be related to the areca alkaloids, which may stimulate the appetite via the inhibition of the GABA receptors [30]; established oral chewing habit can also increase appetite, which contributes to the risk of obesity or insulin resistance $[31,32]$.

A dose-dependent relationship between areca nut use and triglyceride were reported in the Nutrition and Health Survey in Taiwan (1993-1996) [6]. Although we did not detect a significantly higher level of triglyceride in the patients with oral cancer, we noted that current and former areca nut chewers had an elevated triglyceride level, which 
was higher than normal values $(1.7 \mathrm{mM})$. In addition, a significantly lower level of HDL-C was also found in current areca nut chewers (Table 2). One possible mechanism of areca nut affecting metabolic processes is that arecoline may inhibit the differentiation of adipose tissue, induce adenylyl-cyclase-dependent lipolysis, and interfere with the insulin signaling pathway associated with glucose uptake, all of which contribute to hyperlipidemia and insulin resistance [33]. Apart from this, areca nut also increases the lipid profile burden through increasing oxidative stress and inflammation (Table 4). Although we cannot clarify the causal relationship between oxidative stress, inflammation, and the risk for MS in this cross-sectional study, the harmful effects of the areca nut were obvious in the patients with oral cancer who were currently chewing or had formerly chewed areca nut.

Since higher levels of oxidative stress and inflammation are significantly correlated with an increased risk of MS [34], antioxidant administration for patients with oral cancer are worth considering as intervention strategies. Antioxidants can reduce oxidative damage and inflammation, delay cancer progression, and prevent cancer recurrence by scavenging free radicals [35]. Many studies have successfully used vitamins or phytochemicals as antioxidative adjuvants for head and neck squamous cell carcinoma $[36,37]$. Antioxidative nutrients, which can also be obtained from a healthy diet that includes plenty of fresh vegetables and fruits, have been proposed to reduce the risk of head and neck cancer [38]. Recently, a national survey from the US (NHANES 2001-2006) reported that antioxidant levels were inversely associated with the risk of MS and other related parameters, such as insulin resistance, elevated CRP, or hyperuricemia [39], as well as dietary antioxidants, which were also related to a lower prevalence of MS [40]. Thus, further intervention studies should focus on antioxidant supplementation in patients with oral cancer and on monitoring their antioxidant status, particularly individuals with a history of areca nut chewing.

\section{Conclusions}

In conclusion, oral cancer patients with a history of areca nut chewing may present higher levels of oxidative stress and inflammation, even after quitting. As higher oxidative stress and inflammation status may be correlated with an increased risk of MS, we recommend that patients with oral cancer not only stop areca nut chewing but also consume an antioxidant-rich diet, which might help reduce oxidative stress and inflammation and thereby lower the risk of MS.

\section{Data Availability}

The datasets generated and/or analyzed during the current study are available from the corresponding author on reasonable request.

\section{Conflicts of Interest}

The authors declare no conflicts of interest.

\section{Acknowledgments}

This study was supported by grants from the Ministry of Health and Welfare, Taiwan (MOHW103-TD-B-111-10, MOHW104-TDU-B-211-124004, MOHW105-TDU-B-211134002, MOHW106-TDU-B-211-144002, and MOST 1052628-B-040-004-MY2). The authors would like to express our sincere appreciation to the subjects for their participation. The authors also thank the nurses at Taichung Veterans General Hospital for providing their expertise in blood sample collection.

\section{References}

[1] R. L. Siegel, K. D. Miller, and A. Jemal, "Cancer statistics, 2017," CA-Cancer Journal for Clinicians, vol. 67, no. 1, pp. 7-30, 2017.

[2] B. W. Stewart and C. P. Wild, World Cancer Report 2014, IARC Nonserial Publication, Lyon Cedex, France, 2014.

[3] Taiwan's Leading Causes of Death in 2016, "Ministry of Health and Welfare in Taiwan," https://www.mohw.gov.tw/ cp-3425-33347-2.html.

[4] S. Warnakulasuriya, C. Trivedy, and T. J. Peters, "Areca nut use: an independent risk factor for oral cancer," $B M J$, vol. 324, no. 7341, pp. 799-800, 2002.

[5] J. H. Jeng, M. C. Chang, and L. J. Hahn, "Role of areca nut in betel quid-associated chemical carcinogenesis: current awareness and future perspectives," Oral Oncology, vol. 37, no. 6, pp. 477-492, 2001.

[6] J. Y. Guh, L. Y. Chuang, and H. C. Chen, "Betel-quid use is associated with the risk of the metabolic syndrome in adults," The American Journal of Clinical Nutrition, vol. 83, no. 6, pp. 1313-1320, 2006.

[7] F. Javed, K. Al-Hezaimi, and S. Warnakulasuriya, "Areca-nut chewing habit is a significant risk factor for metabolic syndrome: a systematic review," The Journal of Nutrition, Health \& Aging, vol. 16, no. 5, pp. 445-448, 2012.

[8] K. Shafique, M. Zafar, Z. Ahmed, N. A. Khan, M. A. Mughal, and F. Imtiaz, "Areca nut chewing and metabolic syndrome: evidence of a harmful relationship," Nutrition Journal, vol. 12, no. 1, p. 67, 2013.

[9] T. Yamada, K. Hara, and T. Kadowaki, "Chewing betel quid and the risk of metabolic disease, cardiovascular disease, and all-cause mortality: a meta-analysis," PLoS One, vol. 8, no. 8, article e70679, 2013.

[10] T. H. Tung, Y. H. Chiu, L. S. Chen et al., “A population-based study of the association between areca nut chewing and type 2 diabetes mellitus in men (Keelung Community-Based Integrated Screening Programme No. 2)," Diabetologia, vol. 47, no. 10, pp. 1776-1781, 2004.

[11] W. Y. Lin, T. Y. Chiu, L. T. Lee, C. C. Lin, C. Y. Huang, and K. C. Huang, "Betel nut chewing is associated with increased risk of cardiovascular disease and all-cause mortality in Taiwanese men," The American Journal of Clinical Nutrition, vol. 87, no. 5, pp. 1204-1211, 2008.

[12] W. C. Tsai, M. T. Wu, G. J. Wang et al., "Chewing areca nut increases the risk of coronary artery disease in Taiwanese men: a case-control study," BMC Public Health, vol. 12, no. 1, p. 162, 2012.

[13] P. A. Cerutti, "Prooxidant states and tumor promotion," Science, vol. 227, no. 4685, pp. 375-381, 1985. 
[14] J. P. Kehrer, "Free radicals as mediators of tissue injury and disease," Critical Reviews in Toxicology, vol. 23, no. 1, pp. 21-48, 1993.

[15] J. H. Jeng, Y. S. Ho, C. P. Chan et al., "Areca nut extract up-regulates prostaglandin production, cyclooxygenase- 2 mRNA and protein expression of human oral keratinocytes," Carcinogenesis, vol. 21, no. 7, pp. 1365-1370, 2000.

[16] N. A. Botsoglou, D. J. Fletouris, G. E. Papageorgiou, V. N. Vassilopoulos, A. J. Mantis, and A. G. Trakatellis, "Rapid, sensitive, and specific thiobarbituric acid method for measuring lipid peroxidation in animal tissue, food, and feedstuff samples," Journal of Agricultural and Food Chemistry, vol. 42, no. 9, pp. 1931-1937, 1994.

[17] D. Paglia and W. Valentine, "Studies on the quantitative and qualitative characterization of erythrocyte glutathione peroxidase," The Journal of Laboratory and Clinical Medicine, vol. 70, no. 1, pp. 158-169, 1967.

[18] S. Marklund and G. Marklund, "Involvement of the superoxide anion radical in the autoxidation of pyrogallol and a convenient assay for superoxide dismutase," European Journal of Biochemistry, vol. 47, no. 3, pp. 469-474, 1974.

[19] H. Aebi, "Catalase in vitro," Methods in Enzymology, vol. 105, pp. 121-126, 1984.

[20] Y. C. Ko, Y. L. Huang, C. H. Lee, M. J. Chen, L. M. Lin, and C. C. Tsai, "Betel quid chewing, cigarette smoking and alcohol consumption related to oral cancer in Taiwan," Journal of Oral Pathology \& Medicine, vol. 24, no. 10, pp. 450-453, 1995.

[21] A. M.-F. Yen, Y.-H. Chiu, L.-S. Chen et al., "A populationbased study of the association between betel-quid chewing and the metabolic syndrome in men," The American Journal of Clinical Nutrition, vol. 83, no. 5, pp. 1153-1160, 2006.

[22] T. H.-H. Chen, Y.-H. Chiu, and B. J. Boucher, "Transgenerational effects of betel-quid chewing on the development of the metabolic syndrome in the Keelung Community-Based Integrated Screening Program," The American Journal of Clinical Nutrition, vol. 83, no. 3, pp. 688-692, 2006.

[23] J. H. Jeng, Y. J. Wang, W. H. Chang et al., "Reactive oxygen species are crucial for hydroxychavicol toxicity toward $\mathrm{KB}$ epithelial cells," Cellular and Molecular Life Science CMLS, vol. 61, no. 1, pp. 83-96, 2004.

[24] M. C. Chang, C. P. Chan, Y. J. Chen et al., "Areca nut components stimulate ADAM17, IL- $1 \alpha$, PGE2 and 8-isoprostane production in oral keratinocyte: role of reactive oxygen species, EGF and JAK signaling," Oncotarget, vol. 7, no. 13, pp. 16879-16894, 2016.

[25] J. H. Jeng, S. Y. Chen, C. H. Liao et al., "Modulation of platelet aggregation by areca nut and betel leaf ingredients: roles of reactive oxygen species and cyclooxygenase," Free Radical Biology and Medicine, vol. 32, no. 9, pp. 860-871, 2002.

[26] J. H. Jeng, Y. J. Wang, B. L. Chiang et al., "Roles of keratinocyte inflammation in oral cancer: regulating the prostaglandin E2, interleukin- 6 and TNF- $\alpha$ production of oral epithelial cells by areca nut extract and arecoline," Carcinogenesis, vol. 24, no. 8, pp. 1301-1315, 2003.

[27] M. C. Chang, H. L. Wu, J. J. Lee et al., "The induction of prostaglandin $\mathrm{E}_{2}$ production, interleukin-6 production, cell cycle arrest, and cytotoxicity in primary oral keratinocytes and $\mathrm{KB}$ cancer cells by areca nut ingredients is differentially regulated by MEK/ERK activation," Journal of Biological Chemistry, vol. 279, no. 49, pp. 50676-50683, 2004.
[28] C. Y. Yeh, C. L. Lin, M. C. Chang et al., "Differences in oral habit and lymphocyte subpopulation affect malignant transformation of patients with oral precancer," Journal of the Formosan Medical Association, vol. 115, no. 4, pp. 263-268, 2016.

[29] B. J. Boucher, S. W. B. Ewen, and J. M. Stowers, "Betel nut (Areca catechu) consumption and the induction of glucose intolerance in adult CD1 mice and in their F1 and F2 offspring," Diabetologia, vol. 37, no. 1, pp. 49-55, 1994.

[30] B. J. Boucher and N. Mannan, "Metabolic effects of the consumption of Areca catechu," Addiction Biology, vol. 7, no. 1, pp. 103-110, 2002.

[31] N. Mannan, B. J. Boucher, and S. J. W. Evans, "Increased waist size and weight in relation to consumption of Areca catechu (betel-nut); a risk factor for increased glycaemia in Asians in east London," British Journal of Nutrition, vol. 83, no. 3, pp. 267-275, 2000.

[32] W. C. Chang, C. F. Hsiao, H. Y. Chang et al., "Betel nut chewing and other risk factors associated with obesity among Taiwanese male adults," International Journal of Obesity, vol. 30, no. 2, pp. 359-363, 2006.

[33] H. F. Hsu, T. C. Tsou, H. R. Chao et al., "Effects of arecoline on adipogenesis, lipolysis, and glucose uptake of adipocytes-a possible role of betel-quid chewing in metabolic syndrome," Toxicology and Applied Pharmacology, vol. 245, no. 3, pp. 370-377, 2010.

[34] S. J. Chen, C. H. Yen, Y. C. Huang, B. J. Lee, S. Hsia, and P. T. Lin, "Relationships between inflammation, adiponectin, and oxidative stress in metabolic syndrome," PLoS One, vol. 7, no. 9, article e45693, 2012.

[35] R. Sarangarajan, S. Meera, R. Rukkumani, P. Sankar, and G. Anuradha, "Antioxidants: friend or foe?," Asian Pacific Journal of Tropical Medicine, vol. 10, no. 12, pp. 1111-1116, 2017.

[36] L. L. Eastham, C. M. Howard, P. Balachandran, D. S. Pasco, and P. P. Claudio, "Eating green: shining light on the use of dietary phytochemicals as a modern approach in the prevention and treatment of head and neck cancers," Current Topics in Medicinal Chemistry, vol. 18, no. 32, 2018.

[37] A. Jain, A. Tiwari, A. Verma, and S. K. Jain, "Vitamins for cancer prevention and treatment: an insight," Current Molecular Medicine, vol. 17, no. 5, pp. 321-340, 2017.

[38] C. C. Chang, W. T. Lee, Y. C. Lee et al., "Investigating the association between diet and risk of head and neck cancer in Taiwan," Oncotarget, vol. 8, no. 58, pp. 98865-98875, 2017.

[39] M. A. Beydoun, M. R. Shroff, X. Chen, H. A. Beydoun, Y. Wang, and A. B. Zonderman, "Serum antioxidant status is associated with metabolic syndrome among U.S. adults in recent national surveys," The Journal of Nutrition, vol. 141, no. 5, pp. 903-913, 2011.

[40] Y. Li, H. Guo, M. Wu, and M. Liu, "Serum and dietary antioxidant status is associated with lower prevalence of the metabolic syndrome in a study in Shanghai, China," Asia Pacific Journal of Clinical Nutrition, vol. 22, no. 1, pp. 60-68, 2013. 


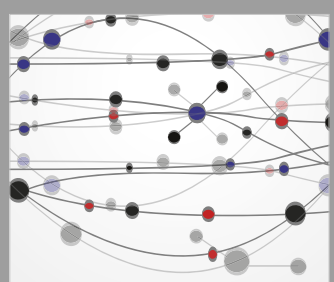

The Scientific World Journal
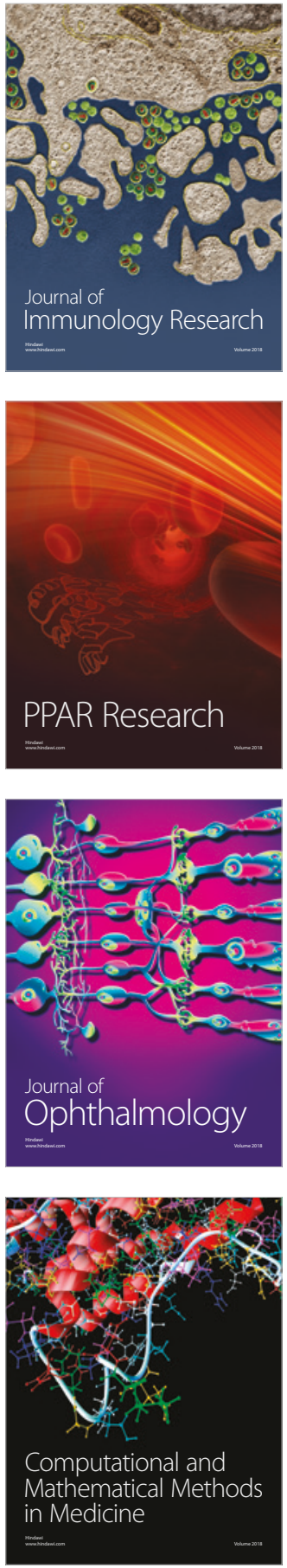

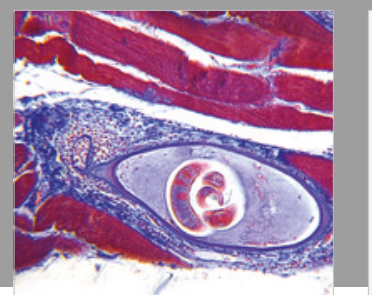

Gastroenterology Research and Practice

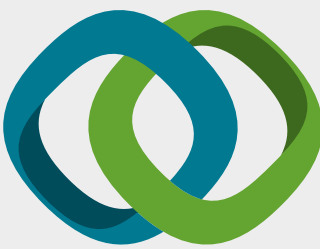

\section{Hindawi}

Submit your manuscripts at

www.hindawi.com
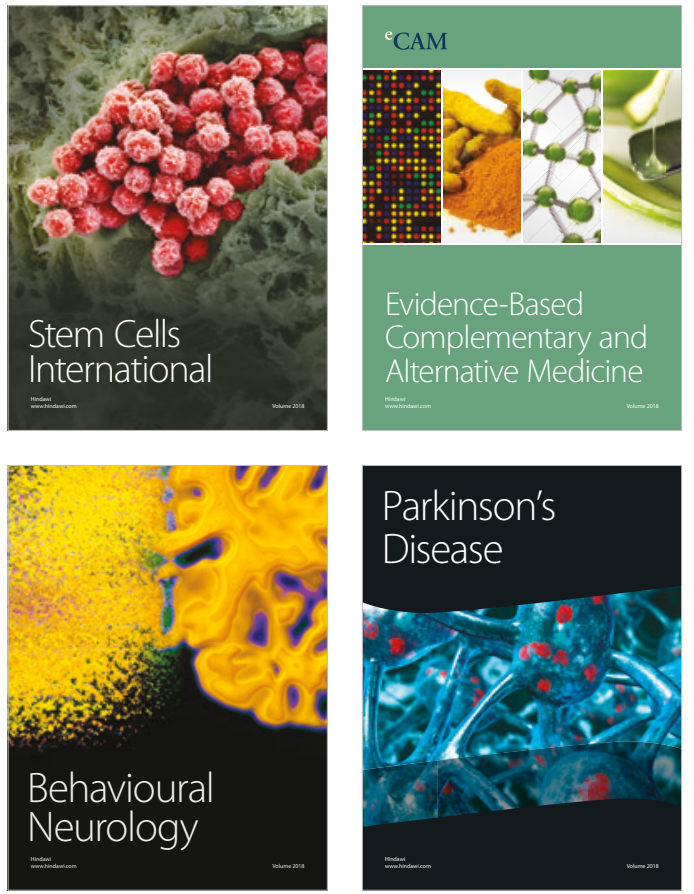

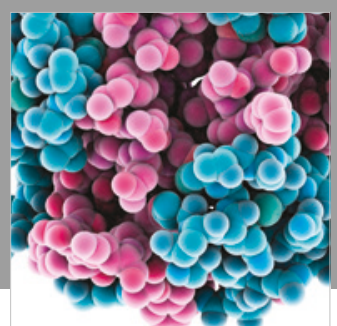

ournal of

Diabetes Research

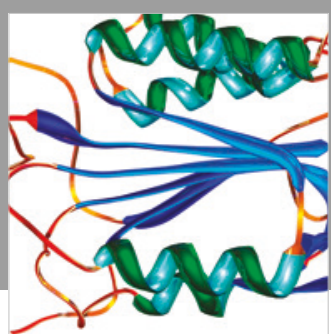

Disease Markers
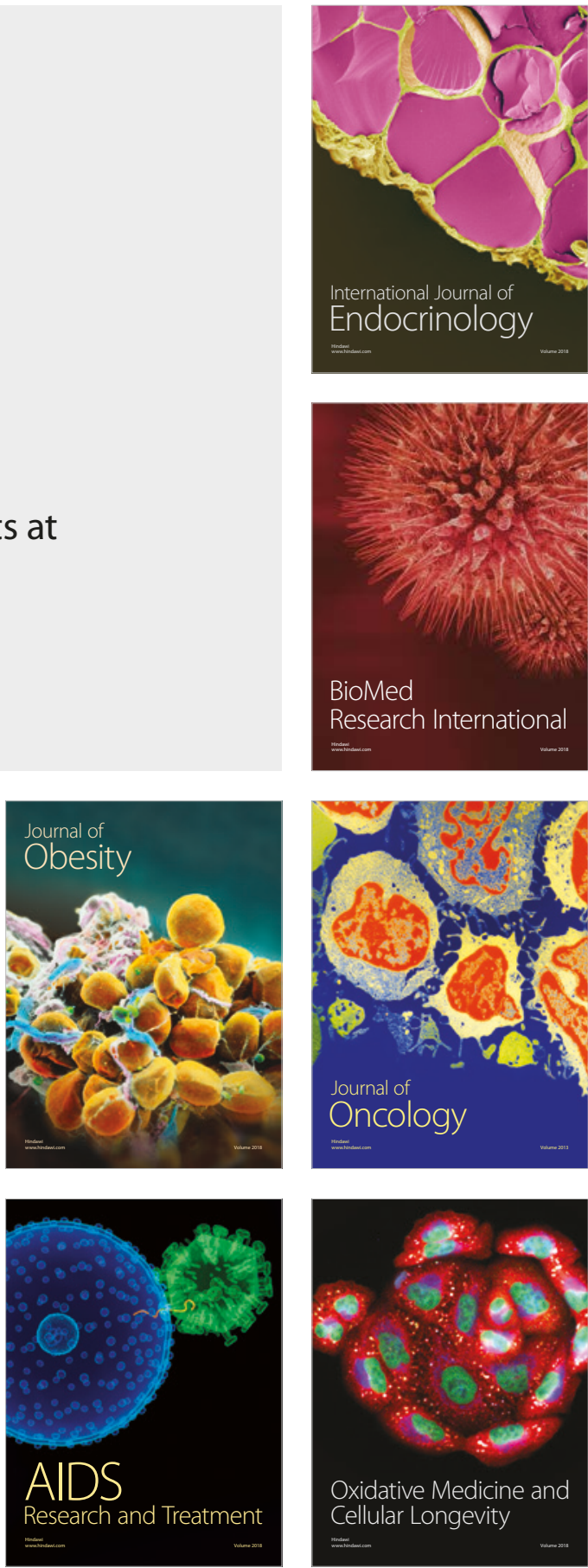